\title{
Large Anterior Lumbar-Sacral Meningocele
}

\author{
lyengar SN, Avdesh Shukla, Ajay Singh* and Sumit Raj \\ Department of Neurosurgery, Gajara Raja Medical Gollege, Gwalior, India
}

\begin{abstract}
An anterior sacral meningocele is a rare form of spinal dysraphism that is sometimes associated with syndromes such as Currarino and Marfan syndromes. These lesions rarely causes neurological complications, but meningitis, sepsis, obstetric problems, and bowel and bladder difficulties are common secondary conditions, surgical treatment is the standard for symptomatic or growing masses as these lesions usually do not regress spontaneously. Anterior or posterior approaches are used to repair the dural defect.
\end{abstract}

We present a case of a $14 \mathrm{yr}$-old female patient with a giant nonsyndromic anterior sacral meningocele that we successfully treated using an open posterior approach. We discuss the treatment options and present a brief review of the literature.

Keywords: Anterior sacral meningocele; Currarino syndrome

\section{Case Report}

We recently had $14 \mathrm{yr}$ female presented with complaint of progressive enlargement of abdomen since childhood. There were no associate neurological, urological or gynaecological symptoms. On examination there was generalised enlargement of abdomen not confined to any quadrant, no tenderness, fluid thrill was present. CT and MRI whole abdomen showed congenital anomalies involving lower lumber vertebrae with partial butterfly $\mathrm{L} 4$ vertebrae and bifurcated body of L5 vertebra, bony defect in sacrum anteriorly on left side with protrusion of meninges through the defect and large unilocular cyst in abdominopelvic region reaching lower part of epigastric region superiorly containing fluid, no sizeable solid component or neural component seen in the sac and there was only right side single kidney and therefore diagnosed as anterior meningocele [1,2](Figure 1).

Patient underwent L4, L5, and S1 laminectomy. There was about anterior dural defect against the body of L4, L5 vertebrae and upper part of sacrum. The clear fluid from the defect was aspirated and the defect was closed (Figure 2). Dural defect was repaired with the placement of fascia with few stay suture was applied both sides of dura. Water tight closure was not possible because nerve roots were passing from the defect. Patient was discharged on seventh day of surgery. Patient came back to us follow up after fifteen days of discharge and repeat MRI was done which showed that dural defect was closed and there was no communication between the thecal sac and the intraabdomial part of meningocele and the size of intraabdomial cavity was also reduced markedly.

\section{Introduction}

Anterior sacral meningocele is rare congenital anomaly which was first described in 1837 by Bryant [3]. Anterior meningocele is unilocular or multilocular extension or herniation of the duramater and arachnoid out of the sacral spinal canal through the defect in the sacrum into the retroperitoneum and intraperitoneal space, either anteriorly through the body of sacrum or anterolateraly through the enlarged intervertebral foramina or coalesced foramina. It contains cerebrospinal fluid. Mostly present before the third decade of life and more common in females [4].

\section{Discussion}

Anterior sacral meningocele is uncommon congenital malformation usually associated with sacrococcygeal bony defect anteriorly with protrusion of dural sac anterior through the defect. First case of anterior sacral meningocele was described by Bryant in 1837 [3]. Anterior sacral meningocele is a lesion which consists of a cerebrospinal fluid sac in the pelvic cavity communicating by the subarachnoid fistula through the sacral defect. It is recognised within the heritable

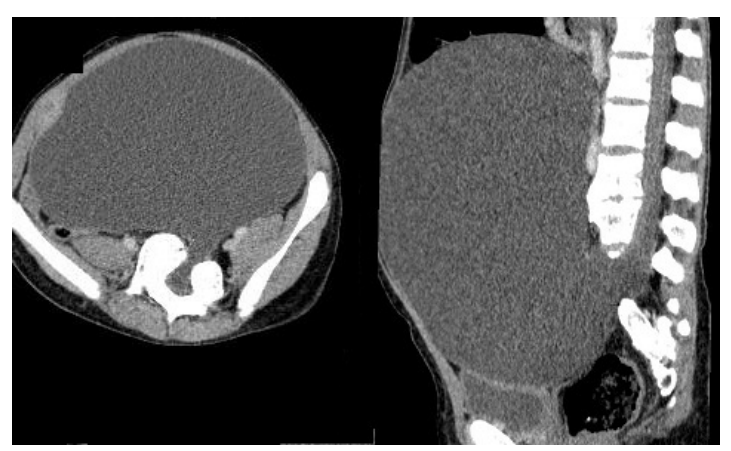

Figure 1: CT scan of abdomen showing bony defect in sacrum anteriorly on left side with protrusion of meninges through the defect and large unilocular cyst no neural component seen in the sac and there was only right side single kidney.

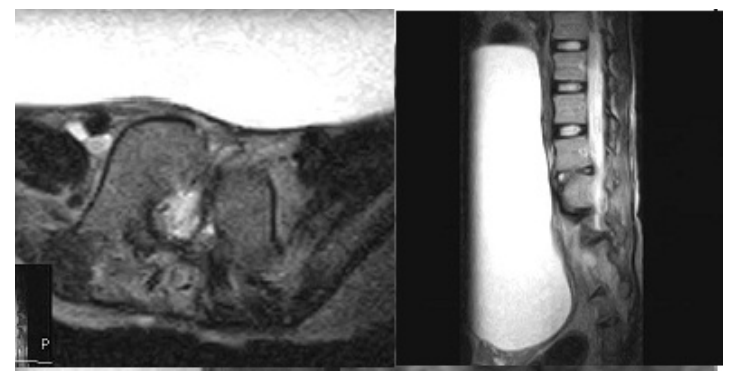

Figure 2: Post operative MRI closure of dural defect with reduction in size of the intraabdominal cyst.

*Corresponding author: Ajay Singh, Department of Neurosurgery, Gajara Raja Medical College, Gwalior, India, E-mail: drajaysinghkgmc@gmail.com

Received May 02, 2013; Accepted May 28, 2013; Published May 30, 2013

Citation: lyengar SN, Shukla A, Singh A, Raj S (2013) Large Anterior LumbarSacral Meningocele. J Spine S2: 003. doi:10.4172/2165-7939.S2-003

Copyright: (C) 2013 lyengar SN, et al. This is an open-access article distributed under the terms of the Creative Commons Attribution License, which permits unrestricted use, distribution, and reproduction in any medium, provided the original author and source are credited. 
currarino triad, consisting of congenital anal stenosis, scimitar sacrum and a presacral mass. May be associated with the variety of congenital anomalies of the pelvis including: anorectal malformation, dermoid cysts, sacrococcygeal teratoma and lipoma, duplication of urogenital tracts and epidermoid tumours [5].

Anterior sacral meningocele mostly result from failure of fusion of sacrum with subsequent herniation of the sacrum meninges into the sacral hollow. The possible mechanism leading to anterior sacral meningocele as:

\section{a) Congenital:}

1) Sacral bone defect

2) Proliferation of arachnoid

3) Connective tissue disorder

b) Degenerative: ischemic lesion

c) Traumatic: nerve root avulsion or haemorrhage

d) Iatrogenic: during surgery

Symptoms may include:

-chronic constipation

-urinary incontinence

-dysmenorrhoea

-dysperunia

-chronic low backache

-abdominal, pelvic, gluteal or groin masses

-bacterial meningitis

-headache

-sacral numbness

-lower extremity paresthesia

-anal sphincter disturbances

X-ray, Myelography, CT scan, MRI scan are useful in delineating the anatomy of the stalk and planning of the surgical operation for the meningocele. CT scan and MRI scan are the investigation of choice
[6]. 'Scimitar' sign a smooth curved unilateral sacral defect simulating shape of Arabic sabre on plain X-ray is considered to be pathognomic of anterior sacral meningocele. Abdominal and spinal sonography should be the first diagnostic investigation and can diagnose anterior sacral meningocele and differentiate it from other cytic lesions in the pelvis.

Good clinical examination and radiological investigation should be able to differentiate anterior sacral meningocele from other causes of cystic presacral masses in children which include a) sacrococcygeal teratoma; b)tumours like dermoid, lipomas, neuroblastoma; c) neuroectodermal cyst; d) rectal duplication cyst; e) ovarian cyst; f) pelvic kidney.

Surgical closure is the treatment of choice, because the anterior meningocele does not have spontaneous regression and generally progresses its enlargement with a corresponding increase in the risk of complications. The goal in the treatment of anterior meningocele is the obliteration of the communication between the spinal subarachnoid space and the meningocele. Reported procedure are posterior approach to perform sacral laminectomy and tie of the neck of the anterior sacral meningocele, transabdominal approach with the oversewing of the neck of the meningocele, and perineal approach, and lumboperitoneal shunt insertion in large fistula with unsuccessful surgical closure [7].

\section{References}

1. Raftopoulos C, Pierard GE, Rétif C, Braude P, Brotchi J (1992) Endoscopic cure of a giant sacral meningocele associated with Marfan's syndrome: case report. Neurosurgery 30: 765-768.

2. Strand RD, Eisenberg HM (1971) Anterior sacral meningocele in association with Marfan's syndrome. Radiology 99: 653-654.

3. Bryant $T$ (1837) Case of deficiency of the anterior part of the sacrum with a thecal sac in the pelvis similar to the tumour of spina bifida. Lancet 1: 358

4. Villarejo F, Scavone C, Blazquez MG, Pascual-Castroviejo I, Perez-Higueras A, et al. (1983) Anterior sacral meningocele: review of the literature. Surg Neurol 19: 57-71.

5. Wilkins RH (1996) Lateral and anterior sacral meningoceles in Wilkins $\mathrm{R} H$ Regachary SS eds neurosurgery, (2ndedn) Mcgraw-Hills, New York.

6. Fitzpatrick MO, Taylor WA (1999) Anterior sacral meningocele associated with a rectal fistula. Case report and review of the literature. J Neurosurg 91: 124127.

7. Rukskul P (2005) Lumbo-peritoneal shunting improved spinal cord compression due to a large anterior sacral meningocele. J Med Assoc Thai 88: 265-268. 